\title{
OS MOVIMENTOS DE MULHERES NO BRASIL E A RELAÇÃO COM A POLÍTICA EXTERNA BRASILEIRA (2003 - 2015)
}

\author{
WOMEN'S MOVEMENTS IN BRAZIL AND THEIR RELATIONSHIP WITH \\ BRAZILIAN FOREIGN POLICY (2003 - 2015)
}

DOI: 10.5380/cg.v9i2.73014

Vanessa Marx ${ }^{2}$

Gabriela Luiz Scapini3

Joana Winckler4

\begin{abstract}
Resumo
O artigo propõe verificar a atuação dos movimentos de mulheres no Brasil, sua internacionalização e relação com a política externa brasileira entre os anos de 2003 e 2015, partindo do entendimento de que a política externa pode ser considerada uma política pública. A partir disto, foram pensados três eixos principais para explicar estes fenômenos: a internacionalização dos movimentos sociais e a política externa brasileira; internacionalização dos movimentos de mulheres no Brasil e a relação com o Estado e a atuação internacional dos movimentos de mulheres brasileiras. Em um primeiro momento, foi realizada análise de fontes documentais sobre a participação das mulheres nos canais institucionais de participação e fóruns internacionais. Em um segundo momento, questionários foram aplicados às integrantes de movimentos de mulheres que participaram dos canais institucionais sobre questões de gênero e também atuaram no Fórum Social Mundial em 2015. Os resultados apontaram que a maioria dos movimentos e organizações de mulheres analisadas nesta pesquisa se consideram internacionalizados e participam de redes internacionais, sobretudo em organizações internacionais que tratam das problemáticas das desigualdades de gênero.
\end{abstract}

Palavras-Chave: Movimento de Mulheres; Feminismos; Política Externa Brasileira; Políticas Públicas.

\begin{abstract}
This article proposes to verify the performance of women's movements in Brazil, their internationalization, and their relationship with Brazilian foreign policy between the years 2003 and 2015 and assumes the understanding that foreign policy works as a public policy. Based on this, three main axes were thought to explain these phenomena: the internationalization of social movements and Brazilian foreign policy; internationalization of women's movements in Brazil and the relationship with the State and the international performance of Brazilian women's movements. First, an analysis was made of documentary sources on the participation of women in institutional participation channels and international forums. Next, questionnaires were applied to members of women's movements who participated in institutional channels on gender issues

\footnotetext{
${ }^{1} \mathrm{O}$ presente artigo foi financiado com recursos do Conselho Nacional de Desenvolvimento Científico e Tecnológico (CNPq).

${ }^{2}$ Doutora em Ciência Política e Administração pela Universidad Autonoma de Barcelona (2008) e professora do Programa de Pós-Graduação em Sociologia e do Departamento de Sociologia da Universidade Federal do Rio Grande do Sul (UFRGS). E-mail: vanemarx14@gmail.com. ORCID: https://orcid.org/o0oo-0002-3595$\underline{2883}$.

3 Doutoranda do Programa de Pós-Graduação em Sociologia (PPGS) da Universidade Federal do Rio Grande do Sul. E-mail: gabrielascapini@gmail.com. ORCID: https://orcid.org/o000-0002-7260-3586.

4 Bacharela em Ciências Sociais na Universidade Federal do Rio Grande do Sul (UFRGS). E-mail: joana.winckler@hotmail.com. ORCID: https://orcid.org/0000-0001-8236-1325.
} 
and also worked at the World Social Forum in 2015. The results demonstrate that the majority of women's movements and organizations analyzed in this paper consider themselves internationalized and participate in international networks, especially in international organizations that deal with the problems of gender inequalities.

Keywords: Women's Movement; Feminisms; Brazilian Foreign Policy; Public Policy.

\section{INTRODUÇÃO}

O interesse em estudar os movimentos sociais brasileiros e sua atuação no cenário internacional surge pelas crescentes manifestações e mobilizações internacionais realizadas no final dos anos 90, com as manifestações antiglobalização em Seattle, e que se intensificaram com à crise financeira de 2008. Algumas destas manifestações vêm tensionando e tecendo críticas à política externa de alguns Estados e de organismos internacionais em que o Brasil faz parte. Por outro lado, a política externa brasileira apresentou um caráter inovador durante o período de 2003 a 2014 fazendo com que o país se tornasse uma liderança importante para os países emergentes, criando novas agendas como o combate à pobreza e a desigualdade, e estabelecendo novas estratégias de Cooperação Sul-Sul, como a criação do Fórum IBAS (Índia, Brasil e África do Sul), BRICS (Brasil, Rússia, Índia, China e África do Sul) e a participação ativa no G-20. Estas estratégias refletem a mudança de paradigma da política externa brasileira exercida durante os doze anos de governo do Partido dos Trabalhadores (PT) à frente da Presidência da República. Além da inovação na política externa, o Brasil é visto internacionalmente como referência na criação de canais de participação e de diálogo com os movimentos sociais na gestão pública. Esta inovação em políticas de participação na gestão pública tem sido visibilizada no plano internacional através da participação dos movimentos sociais brasileiros no Fórum Social Mundial e nos canais de institucionais de participação do Estado (MARX, 2015a).

Frente a um contexto de mobilização internacional e inovação de política externa brasileira, a atuação dos movimentos sociais brasileiros na arena internacional se torna complexa. No projeto de pesquisa intitulado, os Movimentos Sociais como atores do sistema internacional, buscamos verificar se os movimentos sociais brasileiros vêm participando do cenário internacional e se estabelecem relações com o Estado para atuação no plano internacional. Nessa direção, pensamos ser pertinente vincular essas temáticas a questão dos movimentos de mulheres no Brasil e identificar como esses vêm se articulando e participando de redes internacionais e criando canais de diálogo com a política externa brasileira. Por esta razão, compreendemos neste artigo que a política externa poderia ser considerada uma política pública (MILANI; PINHEIRO, 2013).

Para tanto, analisamos a atuação dos movimentos de mulheres brasileiras a partir da criação do Fórum Social Mundial em 2001, até o primeiro governo da presidenta Dilma Rousseff (2010 2014) enfatizando a mudança da política externa brasileira no período do governo do presidente Luiz Inácio Lula da Silva (2003-2010) e contemplando o período da crise financeira internacional 
de 2008. Adotamos a metodologia qualitativa composta por análises de documentos oficiais como o I Plano Nacional de Políticas para as Mulheres de 2005 - 2007 e o II Plano Nacional de Políticas para as Mulheres de 2008 e de informações e documentos obtidos no site oficial ONU Mulheres. Esta análise de conteúdo demonstrou que a partir do primeiro mandato do governo da presidenta Dilma Rousseff a agenda das mulheres e a aproximação com o movimento de mulheres ganhou destaque, principalmente com a atuação conjunta nos organismos internacionais, como, por exemplo, a ONU Mulheres. Posteriormente, para verificar como se desenvolvia esta internacionalização, foram respondidos doze questionários por movimentos de mulheres atuantes no Brasil e que participam dos canais institucionais de participação e do Fórum Social Mundial em 2015. Além disso, foram realizadas duas entrevistas em profundidade com representantes de movimento de mulheres que participaram do Fórum Social Temático, realizado em Porto Alegre neste mesmo ano.

A partir destes dados construímos este artigo focando-o em três eixos principais: (a) internacionalização dos movimentos sociais e a política externa brasileira; (b) internacionalização dos movimentos de mulheres no Brasil e a relação com o Estado; e (c) atuação internacional dos movimentos de mulheres brasileiras. $\mathrm{O}$ conjunto dessas análises possibilitaram identificar como tem sido construída a internacionalização dos movimentos de mulheres no Brasil, bem como sua articulação e participação através dos canais institucionais de interlocução com o Estado brasileiro no que se refere à política externa do país e na atuação conjunta em redes para exercer influência na construção de uma agenda feminista internacional.

\section{A INTERNACIONALIZAÇÃO DOS MOVIMENTOS SOCIAIS E A POLÍTICA EXTERNA BRASILEIRA}

Os movimentos sociais atuam no âmbito externo e poderiam ser considerados um novo ator das relações internacionais, pois, segundo Cristina Pecequilo (2004), os novos atores das relações internacionais poderiam ser subdivididos em dois grupos: as organizações internacionais governamentais (ou intergovernamentais), como a Organização das Nações Unidas (ONU) e as forças transnacionais, que podem ser divididas em quatro categorias: as Organizações Não Governamentais (ONG’s), as multinacionais, grupos diversos da sociedade civil e a opinião pública internacional. A partir desta definição de novos atores consideramos que os movimentos sociais poderiam se inserir na categoria de grupos diversos da sociedade civil. Entendemos, neste estudo, como novos atores, os que exercem influência na arena internacional e que, mesmo atuando no cenário das relações internacionais, não fazem parte da estrutura da política exterior do Estado nacional, como seria o caso dos movimentos de mulheres. 
Além de exercer influência no âmbito externo, os movimentos sociais atuam nas localidades, lugar onde expressam desejos, conflitos e disputas com outros atores e buscam espaços para participar do processo de formulação e implementação de políticas públicas de Estado. Apesar do território ser o lugar onde exercem a ação política e suas lutas, a globalização vem internacionalizando as agendas dos movimentos sociais (MARX, 2015a). A literatura específica sobre as teorias dos movimentos sociais, busca explicar as lutas, motivações e confrontos de atores como o movimento de mulheres por meio de diferentes abordagens: ciclos de protestos e estruturas de mobilização política (TARROW, 2009; TILLY, 1978), ação social (TOURRAINE, 1985), identidade coletiva (MELUCCI, 1989), redes de movimentos sociais (SCHERER-WARREN, 2006) e ativismo na relação entre Estado e sociedade (ABERS; VON BÜLOW, 2011). A inovação vinda dos movimentos sociais consistiria na busca pela ampliação da esfera pública através da multiplicação de experiências de democracia participativa, da inserção dos atores sociais excluídos e da criação de canais de diálogo entre os saberes populares intrínsecos nas lutas e nas práticas do cotidiano dos movimentos.

O contexto mundial recebe influência, nas últimas décadas, da chamada globalização. Este fenômeno vem influenciando cada vez mais as dinâmicas sociais intensificando as relações e interdependências globais (MARX, 2015a). Os fatores econômicos se apresentam como a variável principal, ficando o poder político algumas vezes refém da economia onde a expressão máxima se traduz na subordinação de alguns Estados às forças do capital, das empresas transnacionais e dos mercados financeiros.

O Fórum Social Mundial se constituiu durante muitos anos como arena de encontro dos movimentos sociais e foi gradualmente propondo uma globalização alternativa a globalização neoliberal, uma globalização contra-hegemônica, que Boaventura de Sousa Santos (2002, p.57) definiu da seguinte maneira:

Globalização contra-hegemônica seria a articulação transnacional dos movimentos, associações e organizações que defendem os interesses e grupos subalternos ou marginalizados pelo capitalismo global. A globalização contra-hegemônica é fundamental para organizar e disseminar estratégias, políticas eficazes, criar alternativas ao livre comércio como às iniciativas de comércio justo, e garantir o acesso das ONG's dos países periféricos ao conhecimento teórico e as redes políticas onde emergem as políticas hegemônicas que afetam a estes países.

O conceito de globalização contra-hegemônica nos ajuda a pensar na inserção dos movimentos sociais brasileiros no cenário internacional, assim como a perspectiva decolonial. Em linhas gerais, podemos afirmar que o movimento de mulheres no Brasil e na América Latina comunga da perspectiva decolonial na medida que explicita formas de opressão e de discriminação simbólica muito particulares deste continente que foram sendo construídas pelo patriarcado. Em especial naquilo que Segato (2012) define como a colonialidade de gênero, a qual abrange a interrelação entre colonialidade e patriarcado expressa na organização social latino-americana. 
Nesse sentido, a recuperação do papel do Estado começou a abrir o debate na América Latina sobre a necessidade de definição de uma agenda pós-colonial para o continente e a implantação de políticas alternativas que reforcem a globalização contra-hegemônica (MARX, 2015b). Nesta perspectiva Ilse Scherer-Warren (2010, p. 20) expõe a necessidade de incorporar a literatura do póscolonialismo aos estudos dos movimentos sociais:

Os estudos pós-coloniais ou do pós-colonialismo em certa medida, incorporaram
legados das teorias de classe e das respectivas formas de opressão das elites coloniais
e hegemônicas, das teorias culturalistas, no que diz respeito às múltiplas formas de
opressão e discriminação simbólica em relação aos segmentos sociais colonizados; e
da respectiva exclusão e/ou subalternidade destes segmentos no plano do fazer
político, no cotidiano societário e nas instituições. Portanto, cabe buscar as
contribuições que os estudos pós-coloniais incorporaram, ainda que criticamente,
das teorias anteriores das ações coletivas e dos movimentos sociais que se
constituíram sob a égide dos referenciais teóricos da modernidade e da pós-
modernidade. Assim será possível analisar o que trouxeram de novidade para pensar
a subalternidade de sujeitos sociais na América Latina e de que forma podem
contribuir para a reflexão sobre as novas formas de inclusão e de exclusão social no
Brasil e na América Latina num sentido mais amplo.

Nessa direção, e em relação a participação desses atores, a autora enfatiza a necessidade de preparar os sujeitos para que se tornem atores de novas formas de governança, ou seja, requer que eles participem de diversos espaços, tais como os de mobilização de uma base local na esfera pública, de fóruns e redes da sociedade civil que ampliem seu empoderamento, na participação de conselhos setoriais de parceria entre a sociedade civil e Estado. Além disso, nos últimos anos, esses atores buscam uma representação ativa em conferências nacionais e globais construídas pela iniciativa governamental em parceria com a sociedade civil organizada (SCHERER-WARREN, 2006, p. 123)

Os movimentos de mulheres se mostram atuantes na arena internacional desde o período da redemocratização e atuaram, por exemplo, em Comitês Internacionais como o Comitê para a Eliminação de todas as Formas de Discriminação contra a Mulher (CEDAW) encaminhando seu primeiro relatório em 2002 (RELATÓRIO NACIONAL BRASILEIRO, 2002). A partir da criação e ampliação dos espaços de articulação entre Estado e sociedade civil, em conferências e fóruns de políticas para mulheres no país, pudemos visibilizar suas agendas e perceber o empoderamento dos movimentos de mulheres e sua influência nas relações internacionais durante este período.

Nesse sentido, essa relação é identificada durante o primeiro mandato do governo Dilma Rousseff, pois os movimentos e redes feministas participaram de espaços como redes e fóruns que discutem as políticas para as mulheres também no âmbito internacional, em conjunto com o governo. Estes espaços de participação no âmbito interno aliados às redes de articulação do movimento de mulheres em nível internacional, por meio da participação nos organismos internacionais, fez com que os movimento de mulheres pudesse trabalhar a agenda no âmbito interno e expô-la no cenário internacional. Para Patrícia Rangel (2012, apud AVELAR, 2013, p. 73): 
As mulheres tiveram sucesso em transitar por distintos espaços e influenciar decisões nos três poderes (...) por meio do novo patamar institucional de intermediação entre Estado e sociedade e de representação nas formas de participação (...) tornando mais claras as relações entre representação substantiva e descritiva das mulheres e o impacto dos movimentos feministas sobre as políticas.

A partir desta forma de articulação e participação ativa nos espaços institucionais de participação, interpretamos que a política externa poderia ser entendida como uma política pública nos termos de Carlos Milani e Letícia Pinheiro (2013) e poderia significar que a política externa brasileira deveria ser estudada também à luz das escolhas dos governos, desvinculando-a de supostos interesses nacionais autoevidentes ou permanentes. Segundo Milani e Pinheiro (2013, p.18), podemos identificar que tanto a ordem internacional quanto a doméstica, apesar das desigualdades e das diferenças que permeiam suas estruturas, mantêm diversos espaços políticos em aberto, esses congregam desde atores estatais não tradicionais, atores:

Tanto a ordem internacional, quanto a doméstica, apesar das desigualdades e das diferenças que conformam suas estruturas, deixam em aberto vários espaços políticos - que envolvem desde atores estatais não tradicionais, atores não estatais com interesses públicos ou coletivos, até determinados grupos ou setores econômicos e culturais da sociedade, como os movimentos sociais. Tornando-se um desafio para a nossa capacidade analítica de localizar com precisão o lócus institucional e o agente par excellence da decisão em matéria de política externa. Fazendo emergir, portanto, a necessidade de uma nova visão sobre a política externa, sua prática e seu estudo (MILANI; PINHEIRO, 2013, p. 24).

Nesse sentido, também se assume que a política externa funciona como uma política pública e, dessa forma, a trazemos para o terreno da politics, em que sua implementação e formulação depende das coalizões, negociações, disputas e acordos que expressam a dinâmica do campo da política. Essa concepção nos permite romper com visões tradicionais sobre a política externa, as quais alegam que essa funcione a partir de interesses nacionais autoevidentes ou permanentes (MILANI; PINHEIRO, 2013, p. 24).

A partir desta lógica, constatamos que a política externa brasileira deveria ser pensada para além do Ministério de Relações Exteriores (MRE), já que este apresenta um caráter insular, onde sua característica de maior destaque seria o seu insulamento burocrático. Como consequência dessa característica, o processo de formação da política externa do MRE tende a ser centralizadora. De acordo com Carlos Faria (2012, p. 318) essa centralização é o resultado da confluência de distintos fatores tais como:

(a) o arcabouço constitucional do país, que concede grande autonomia ao Executivo nesta matéria, relegando o Legislativo a uma posição marginal, o que também ocorre na maior parte dos países; (b) do fato de o Congresso brasileiro ter delegado ao Executivo a responsabilidade pela formação da política externa; (c) do caráter "imperial" do presidencialismo brasileiro; (d) do fato de o modelo de desenvolvimento por substituição de importações ter gerado uma grande introversão e um insulamento dos processos políticos e econômicos do país, redundando em grande isolamento internacional do Brasil, reduzido a partir do 
início da década de 1990; (e) do caráter normalmente não conflitivo e largamente adaptativo da atuação diplomática do país; e, por fim, mas não menos importante, (f) da significativa e precoce profissionalização da corporação diplomática do país, associada ao prestígio de que desfruta o Itamaraty nos planos doméstico e internacional.

Ainda nesta linha de pensamento, para outros autores como Carlos Milani e Maria Regina Lima, “o insulamento burocrático de qualquer agência do Estado democrático enfraquece a própria capacidade de formulação e gestão de políticas governamentais” (LIMA; MILANI 2014, p. 6). A partir deste diagnóstico faz-se necessário investigar sobre a influência e participação dos movimentos e organizações sociais da sociedade civil brasileira nas decisões e posicionamentos do Estado brasileiro em âmbito internacional, principalmente a partir do poder executivo. Para isto, relacionando teoria e empiria, buscou-se verificar, em um primeiro momento, através de análise documental os discursos do primeiro mandato da presidência de Dilma Rousseff e se neles havia preocupação sobre a temática de gênero.

O discurso da Presidente Dilma Rousseff por ocasião do Debate Geral da 66 a Assembleia Geral das Nações Unidas - Nova York, Estados Unidos, 21 de setembro de 2011, reúne todas as pautas de política externa de seu mandato, principalmente em relação às políticas sobre as mulheres:

Pela primeira vez, na história das Nações Unidas, uma voz feminina inaugura o Debate Geral. É a voz da democracia e da igualdade se ampliando nesta tribuna, que tem o compromisso de ser a mais representativa do mundo. É com humildade pessoal, mas com justificado orgulho de mulher, que vivo este momento histórico. Divido esta emoção com mais da metade dos seres humanos deste Planeta, que, como eu, nasceram mulher, e que, com tenacidade, estão ocupando o lugar que merecem no mundo. Tenho certeza, senhoras e senhores, de que este será o século das mulheres.

O discurso proferido no âmbito das Nações Unidas evidencia o interesse político para que a temática de gênero fosse tratada no âmbito internacional, não só pelo caráter pessoal e de seu posto como chefe de Estado, mas também com o crescimento do número de mulheres assumindo posições de poder no mundo. Com isto passamos a verificar como a temática de gênero foi sendo incorporada dentro do Estado e na política interna e ao mesmo tempo problematizada nos fóruns, redes e organismos internacionais de mulheres. No Brasil, a temática invocada na Assembleia Geral da ONU pela Chefe de Estado passou a ser prioridade, junto com a participação dos movimentos de mulheres nos canais institucionais de participação relacionados a políticas de gênero.

\section{INTERNACIONALIZAÇÃO DOS MOVIMENTOS DE MULHERES NO BRASIL E A RELAÇÃO COM O ESTADO}


Os debates em torno das desigualdades de gênero ocupam cada vez mais centralidade desde o primeiro mandato do governo do presidente Luiz Inácio Lula da Silva, que criou um espaço institucional próprio na política para as mulheres. Isto foi visualizado no momento da transferência da Secretaria de Estado dos Direitos da Mulher - vinculada ao Ministério da Justiça - para a Presidência da República, fazendo surgir a Secretaria de Políticas para as Mulheres (SPM), órgão com status de Ministério, que se manteve durante o governo de Dilma Rousseff.

Por outro lado, a política externa priorizou a América do Sul e o Mercosul, a Reforma das Nações Unidas e o fortalecimento das relações com a África (MARX, 2015b). Quanto ao tema da política para mulheres, no âmbito da política externa, os temas prioritários foram o de estimular o empoderamento das mulheres, buscar a inclusão econômica, o reconhecimento de direitos sexuais e reprodutivos e o enfrentamento da violência contra a mulher (MARX, 2015a).

O Conselho Nacional dos Direitos da Mulher, órgão no qual estiveram presentes movimentos e organizações sociais ligadas à questão de gênero, associações e fóruns de mulheres, que participam da elaboração dos Planos Nacionais de Políticas para as Mulheres, também atuam no plano internacional com a participação em importantes organismos, como a Organização das Nações Unidas (ONU), a Organização dos Estados Americanos (OEA), o Mercado Comum do Sul (MERCOSUL), a Comunidade dos Países de Língua Portuguesa (CPLP) e o grupo tripartite IBAS (Brasil, Índia e África do Sul).

Os movimentos e organizações sociais ligados à temática de gênero que fizeram parte do Conselho Nacional dos Direitos da Mulher Gestão 2008-2010 foram: Articulação de Mulheres Brasileiras (AMB), Articulação de ONGs de Mulheres Negras (AMNB), Associação Brasileira de Mulheres de Carreira Jurídica (ABMCJ), Confederação de Mulheres do Brasil (CMB), Federação Nacional dos Trabalhadores Domésticos (FENATRAD), Fórum de Mulheres do Mercosul, Fórum Nacional de Mulheres Negras (FNMN), Liga Brasileira de Lésbicas (LBL), Marcha Mundial de Mulheres (MMM), Movimento Articulado de Mulheres da Amazônia (MAMA), Movimento de Mulheres Camponesas (MMC), Rede Economia e Feminismo (REF), Rede Nacional Feminista de Saúde, União Brasileira de Mulheres (UBM) (BRASIL, 2008).

Caberia, ainda, ressaltar a transversalidade e articulação da temática das desigualdades de gênero como outros temas, assim como o Conselho que é composto por movimentos e organizações sociais ligados a outras temáticas, como no caso da Confederação Nacional dos Trabalhadores na Agricultura (CONTAG), da Confederação Nacional das Trabalhadoras da Indústria (CONTI), a Central dos e das Trabalhadoras do Brasil (CTB), da Central Única dos e das Trabalhadoras (CUT) e da União Nacional dos e das Estudantes (UNE).

A formação desse tipo de órgão institucional de consulta vai de encontro às classificações presentes em Scherer-Warren (2006), quanto aos níveis de participação da sociedade civil. O primeiro refere-se ao associativismo local, ou seja, forças associativas de expressão local ou comunitárias; num segundo nível, encontram-se as formas de articulação inter-organizacionais, 
"que buscam se relacionar entre si para o empoderamento da sociedade civil, representando organizações e movimentos do associativismo local” (SCHERER-WARREN, 2006, p.111). Para a autora é a partir desse tipo de mediação que se dá a interlocução mais institucionalizada entre a sociedade civil e o Estado. Por fim, em um terceiro nível, observa-se as mobilizações na esfera pública. Neste sentido Leila Linhares (1995) discorre sobre o papel dos movimentos sociais:

Os movimentos sociais devem pressionar o Estado brasileiro a dar amplo conhecimento e estimular a discussão em torno de eventos como conferências internacionais além evidentemente de cumprir com os compromissos assumidos. Por outro lado, esses movimentos devem conhecer e debater o conteúdo dos tratados e convenções assinados e particularmente atuar de forma a influenciar o Estado a adotar posições mais avançadas no que se refere principalmente a compromissos que envolvam os direitos humanos e o desenvolvimento econômico e social baseado na equidade (LINHARES, p. 192, 1995).

De fato, podemos perceber a presença no Conselho principalmente de formas de articulação inter-organizacionais. Por exemplo, como aponta Scherer-Warren (2006), a Marcha Mundial das Mulheres (MMM) é um movimento internacional de mulheres fundado nos anos 2000 a partir de uma ampla mobilização de mulheres do mundo todo, as quais se organizaram em campanha contra a pobreza e a violência. Apresenta como princípios a articulação de mulheres no espaço urbano e rural a partir da base formando alianças com outros movimentos sociais. As mulheres são centrais no processo de luta e transformação da sociedade, em especial para "superar o sistema capitalista patriarcal, racista homofóbico e destruidor do meio ambiente" (MARCHA MUNDIAL DAS MULHERES, 2013).

Com isso, observamos que a MMM articula suas estratégias a partir do reconhecimento das múltiplas e plurais desigualdades que afetam a vida das mulheres, sobretudo no combate à pobreza e nas reivindicações de demandar por terra, moradia, acesso ao trabalho digno, a ampliação dos direitos sociais à população, as quais se articulam ao combate às injustiças, como, por exemplo, a luta contra formas de violências que afetam todas as esferas da vida social, seja em relação ao tráfico sexual de mulheres e meninas, ao trabalho escravo ou, até mesmo, o cancelamento da dívida-externa brasileira, essa considerada como uma forma de exploração injusta.

Além das formas de articulação inter-organizacionais, o Conselho Nacional possui um lugar para as conselheiras de notório conhecimento sobre as questões de gênero. Para Lúcia Avelar (2013), que se baseia no pensamento de Joni Lovenduski (2005), para entendermos a representação das mulheres além do âmbito parlamentar e sua presença no Estado devemos pensar no conceito de feminismo de Estado. Segundo a autora:

Ele é definido como 'as atividades de feministas e femocratas nos governos e administrações' ou como o feminismo institucionalizado em agências públicas, ou ainda como a capacidade do Estado em responder às demandas das agências feministas, ou simplesmente como a advocacy dos movimentos de mulheres no âmbito do Estado. Femocratas são feministas que trabalham na burocracia do 
Estado, influenciando o processo político na formação da agenda pública com os temas de interesse das mulheres, incrementando o debate, enfatizando a sua importância para as mulheres e influenciando nas decisões da burocracia do Estado (AVELAR, 2013, p. 76).

A partir do exposto, podemos concluir que o Conselho Nacional dos Direitos da Mulher se tornou um campo interessante para o estudo da articulação entre movimentos e organizações sociais com o Estado brasileiro, inclusive no que tange a política externa, devido a sua participação em organismos internacionais.

\section{O PERFIL E A ATUAÇÃO INTERNACIONAL DOS MOVIMENTOS DE MULHERES BRASILEIRAS}

A pesquisa priorizou a atuação dos movimentos de mulheres no Brasil e sua relação com o cenário internacional, a partir de fóruns e redes internacionais ou de canais de participação de interlocução com o Estado. O recorte temporal foi o de analisar a atuação dos movimentos de mulheres a partir da criação do Fórum Social Mundial em 2001 até o primeiro governo da presidenta Dilma Rousseff (2010 - 2014) enfatizando a mudança da política externa brasileira no período do governo do presidente Luiz Inácio Lula da Silva (2003-2010) e contemplando o período da crise financeira internacional de 2008.

A metodologia adotada na pesquisa foi a qualitativa. Sendo assim, organizamos o trabalho a partir de três etapas complementares. Em um primeiro momento, para melhor diagnosticar como os movimentos de mulheres atuaram no cenário internacional realizamos pesquisa documental. Essa pesquisa foi realizada em documentos oficiais como o I Plano Nacional de Políticas para as Mulheres de 2005 - 2007, o II Plano Nacional de Políticas para as Mulheres de 2008. Assim como análises executadas no site oficial ONU Mulheres. Esses materiais permitiram acessar informações relevantes para esta pesquisa, em especial para o processo inicial em que identificamos como os movimentos de mulheres são retratados nesses documentos. Em um segundo momento, foram aplicados questionários enviados pela internet em que obtivemos resposta de doze representantes do movimento de mulheres. Por fim, o terceiro momento da pesquisa consistiu na realização de duas entrevistas em profundidade com representantes de movimento de mulheres que participaram das atividades do Fórum Social Temático realizado em Porto Alegre no ano de 2015.

Em relação à pesquisa empírica pudemos identificar o perfil e a atuação de alguns movimentos de mulheres brasileiras. As perguntas centrais elaboradas para o questionário foram as seguintes: a) qual é a área de atuação do seu movimento social/organização social? b) qual seria a sua avaliação sobre a participação das organizações/movimentos sociais nas políticas para as mulheres no cenário internacional? c) seu movimento social/organização social é ativo internacionalmente? d) seu movimento social/organização social estabelece redes com outros 
movimentos sociais/organizações sociais? e) seu movimento social/organização social participa de reuniões e negociações da ONU Mulheres? f) o seu movimento social/organização social tem algum contato com o Ministério das Relações Exteriores? g) você considera que o seu movimento social/organização social influencia na Política Externa Brasileira?

O grupo de movimentos de mulheres se identificava com temáticas ligadas às desigualdades de gênero, da mesma forma que articulavam suas discussões em outros temas transversais que envolvem as mulheres, os quais podem ser compartilhados no âmbito internacional, tais como: direitos humanos, comunicação e democratização da mídia, trabalho e raça.

Dessa forma, as análises tanto dos questionários aplicados aos doze movimentos e organizações de mulheres via e-mail como das duas entrevistas em profundidade executadas no Fórum Social Mundial possibilitaram compreender a articulação e influência do movimento de mulheres no cenário internacional. De forma geral, $67 \%$ das entrevistadas apontaram que os movimentos que elas integram são ativos internacionalmente, conforme pode ser observado no Gráfico 1:

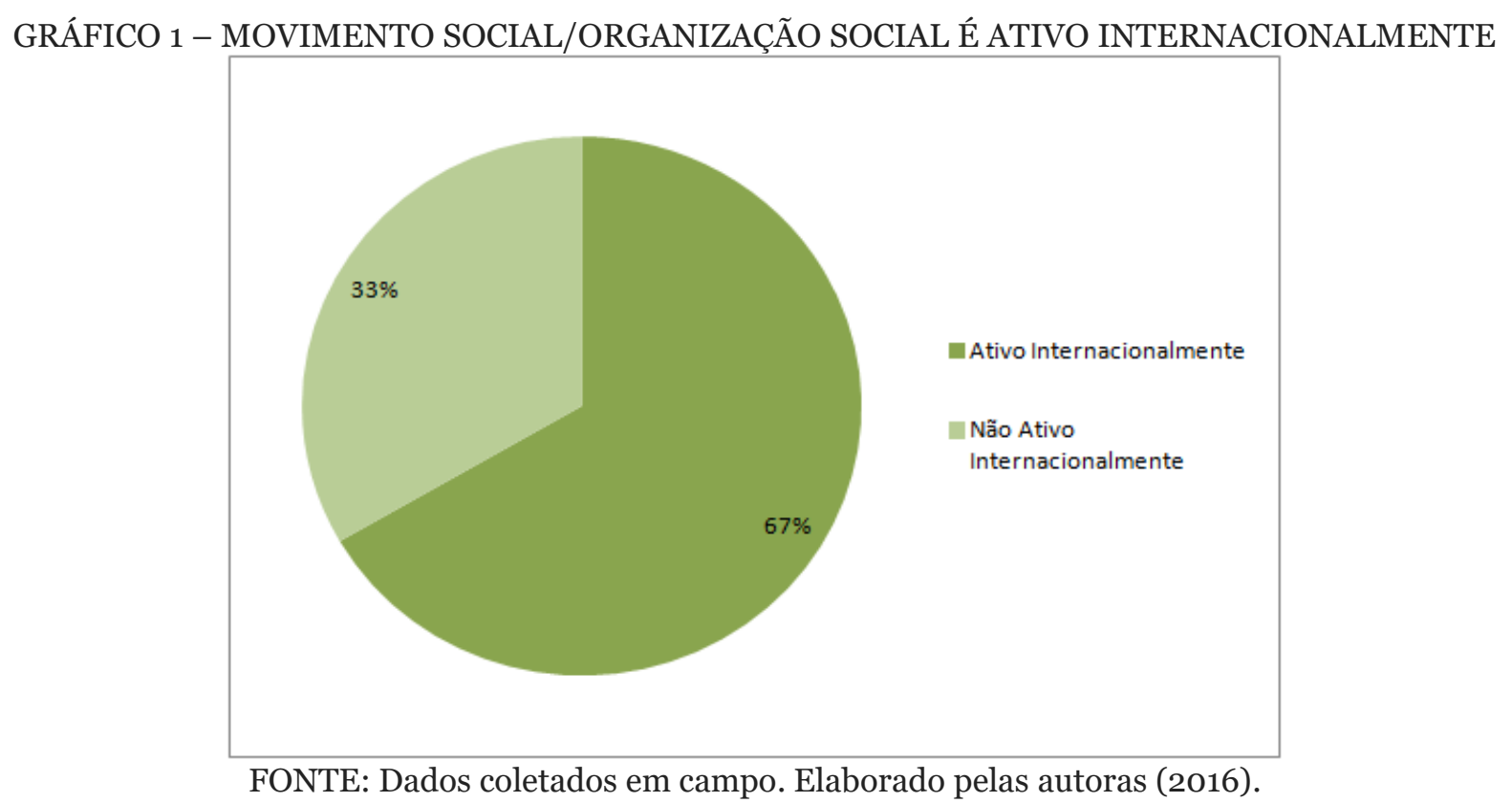

Esta internacionalização se dá por meio da participação em fóruns e organizações internacionais como o Fórum Social Mundial e aqueles que versam sobre a temática dos direitos humanos, na relação com as agências da ONU como a ONU Mulheres, O Programa das Nações Unidas para o Desenvolvimento (PNUD), Centro Internacional de Formação para Autoridades e Líderes (CIFAL) e Instituto das Nações Unidas para Treinamento e Pesquisa (UNITAR), mas verifica-se que a maior articulação para exercer influência no cenário internacional é realizada através da participação em redes internacionais com outros movimentos e organizações sociais tais como: a Marcha Mundial das Mulheres e o Comitê Latino Americano e do Caribe em Defesa dos Direitos das Mulheres (CLADEM). Em geral, essa estratégia de criar coalizões entre diferentes 
organizações e/ou movimentos de mulheres proporciona duas vantagens: na criação de redes de solidariedade internacional entre diferentes movimentos (MOHANTY, 1997) e na possibilidade de exercerem maior influência no cenário internacional, proporcionando o avanço das demandas de mulheres e/ou feministas.

Através das respostas poderia ser possível apontar que a internacionalização desses movimentos, se dá através das "redes de articulação". Esse termo foi utilizado pelas próprias integrantes dos movimentos para expressar as interações entre os movimentos sociais na conformação de espaços como o Fórum Social Mundial, visto como espaço privilegiado de articulação em nível internacional. Em entrevista realizada no Fórum Social Temático 2015, realizado em Porto Alegre, um dos movimentos que articula movimentos de mulheres no Brasil, expressa que esse tipo de espaço é: "um espaço propositivo de ação política para os movimentos sociais e para as mulheres também. De uma forma articulada mundialmente falando”. As respostas dos questionários aplicados apontaram que a formação dessas redes é de suma importância para a agenda dos movimentos de mulheres no Brasil conforme pode-se verificar no Gráfico 2.

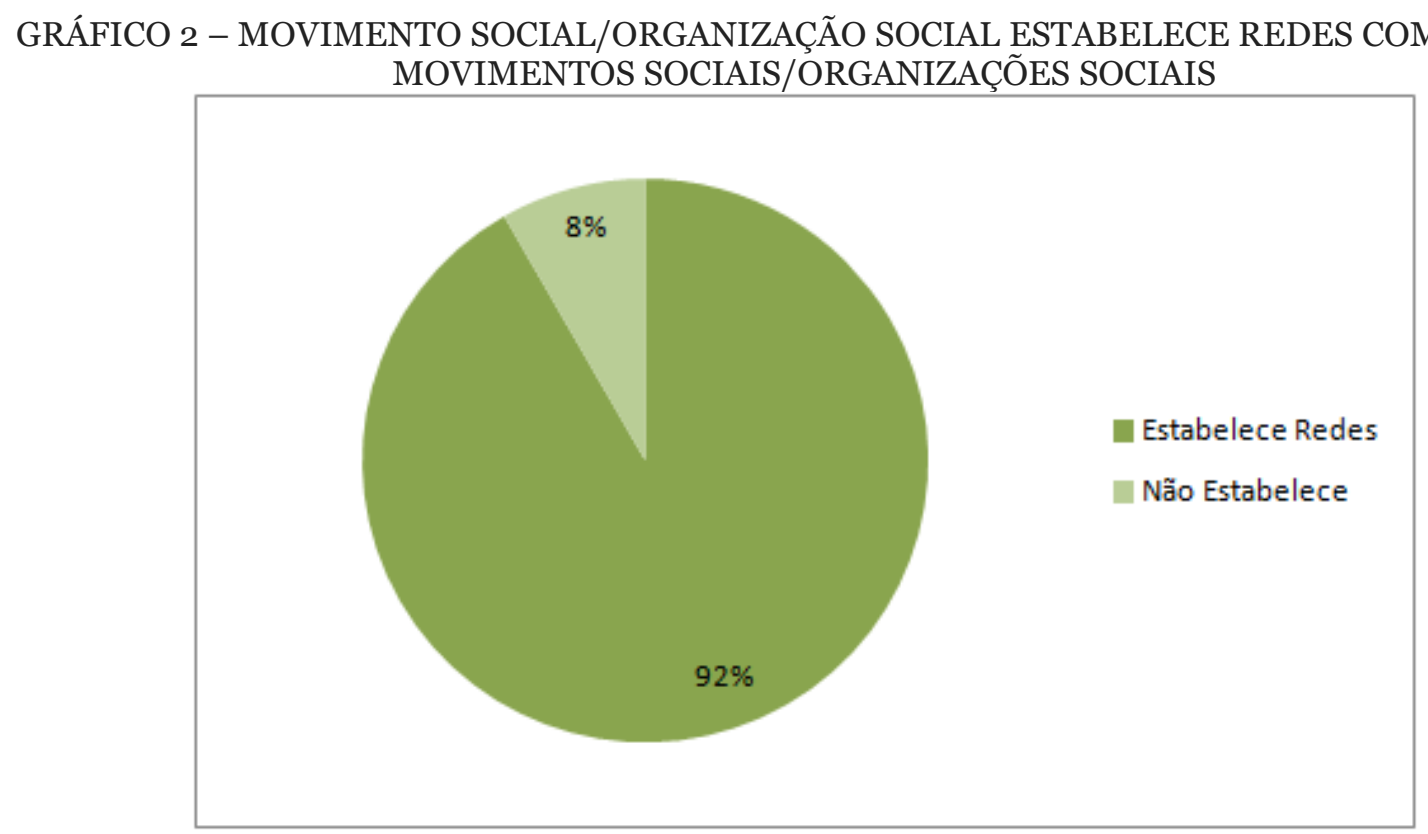

FONTE: Dados coletados em campo. Elaborado pelas autoras (2016).

A análise do conjunto de resposta demonstra que "ser ativo internacionalmente" para os movimentos de mulheres entrevistados nesta pesquisa vai de encontro com o entendimento da própria pesquisa quanto à internacionalização dos movimentos sociais brasileiros, isto é, há um papel relevante desses movimentos na dinâmica internacional, sobretudo em relação às decisões dos Estados-nação, em que as pautas sobre os direitos humanos, lutas LGBT+, demandas do movimento negro, de mulheres entre outros ocorrem, ainda que se reconheça que, majoritariamente, essa internacionalização não se realize via Ministério das Relações Exteriores. Nesse sentido, podemos perceber a importância das temáticas que envolvem as desigualdades de gênero para a construção 
dos movimentos de mulheres, os quais também se interseccionam com outras temáticas que atravessam as experiências de mulheres e homens. Tal relação indica que os movimentos de mulheres brasileiros constroem sua própria agenda feminista, a partir das coalizões que exercem, mas, ao mesmo tempo, atuam transversalmente e exercem influência em outras temáticas e movimentos sociais, sejam estes ligados aos direitos humanos, ao movimento negro, a comunicação e a democratização da mídia, além da articulação junto aos movimentos LGBT+.

A transversalidade de temáticas apresenta-se como um ponto fundamental para entender os próprios movimentos, as redes em que eles se organizam e suas participações em arenas internacionais. A pesquisa indica que essa participação se dá de forma pontual em eventos e congressos organizados pelas organizações internacionais, ou seja, não necessariamente esses movimentos têm "influência permanente" nessas organizações. Por outro lado, abordamos também o viés mais institucional e a relação desses movimentos com o Estado brasileiro, em especial com o Ministério de Relações Exteriores. Em relação a este último, os movimentos sociais entrevistados apontaram pouca ou nenhuma relação conforme demonstra o Gráfico 3.

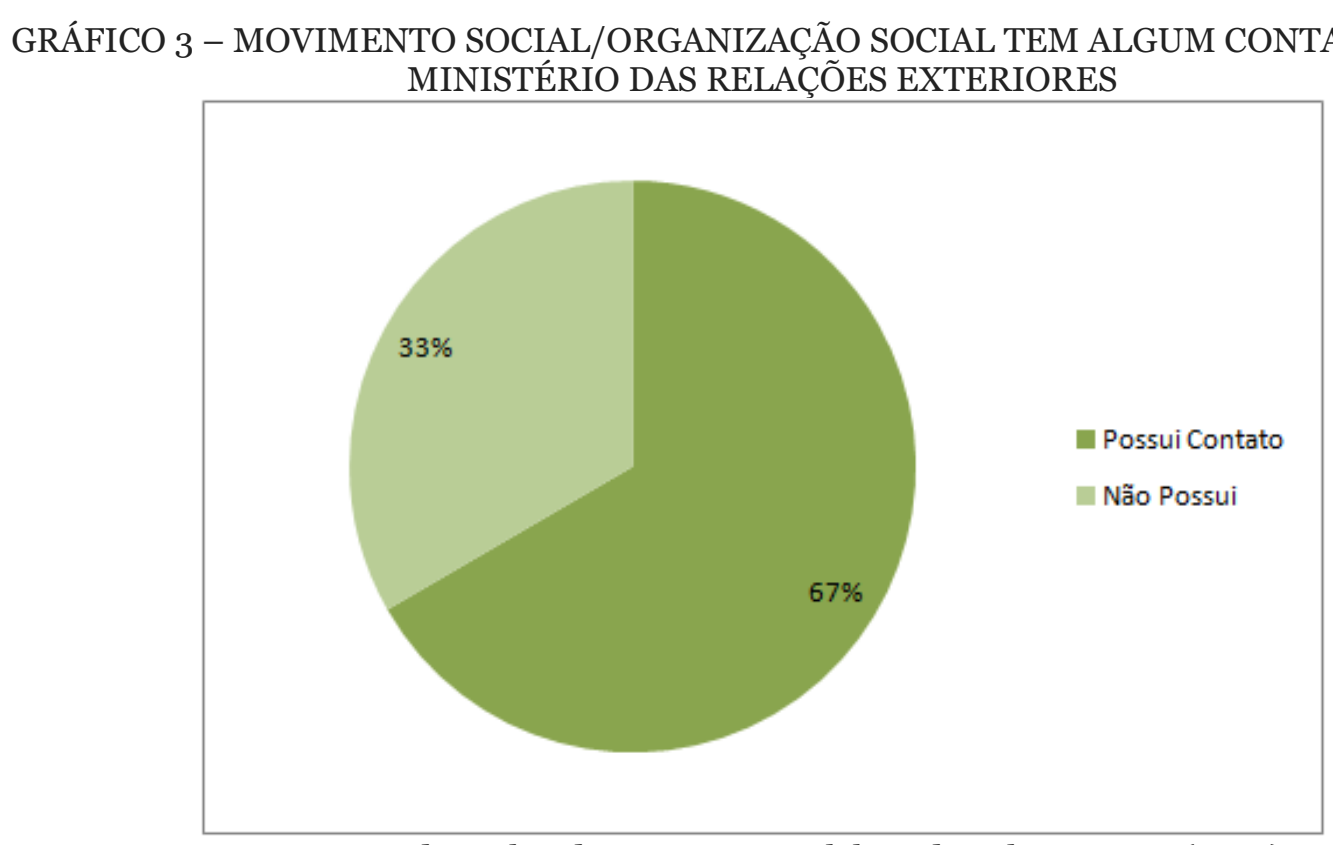

FONTE: Dados coletados em campo. Elaborado pelas autoras (2016).

A pesquisa junto às organizações indica que mais de $33 \%$ dos movimentos analisados não se articula diretamente com o MRE. Esse resultado converge com a perspectiva teórica apresentada neste artigo, onde o MRE apresenta-se ao longo da história como um ministério insular e pouco permeado e influenciado pelos movimentos sociais brasileiros. Já em relação aos organismos internacionais e especialmente a participação na ONU Mulheres a diferença dos movimentos que não participam diminui, mas aponta que 58\% dos movimentos e organizações de mulheres entrevistados não participaram das reuniões e negociações da ONU Mulheres. 


\section{CONSIDERAÇÕES FINAIS}

A pesquisa preocupou-se em articular o debate contemporâneo da globalização hegemônica e contra-hegemônica com os estudos pós-coloniais, a fim de enriquecer a análise da relação dos movimentos de mulheres com o Estado brasileiro a partir de uma visão latino-americana. Pudemos perceber que os movimentos e organizações sociais buscam participar e exercer influência no Estado brasileiro e nos organismos internacionais demonstrando a importância da temática de gênero e a prioridade de suas agendas.

Nesse contexto a problemática da democratização da política externa esteve presente como pano de fundo. A política externa poderia ser tratada como política pública, ainda que o Ministério de Relações Exteriores não tenha criado canais institucionais de participação e diálogo com os movimentos e organizações sociais brasileiros, como por exemplo, um Conselho Consultivo. Além disso, em relação à internacionalização dos movimentos e organizações de mulheres, estes têm atuado de forma paralela articulando-se através de redes e fóruns internacionais próprios.

Verifica-se, ainda, que a presença dos movimentos e organizações sociais no Conselho Nacional dos Direitos da Mulher, evidencia que esses atores criaram um canal de diálogo com o Estado brasileiro, a partir da Presidência da República, utilizando o Conselho como um espaço de influência e participação para pautar suas políticas no âmbito interno e internacional. Desse debate emerge as discussões sobre a política institucional versus a política não institucional. Essas discussões em geral são abordadas de forma dicotômica, como se fossem processos que não se articulam. Porém, em um país como o Brasil em que o chamado "trânsito institucional" é intenso, faz-se necessário analisar com mais atenção a relação e o diálogo entre o Estado brasileiro e os movimentos e organizações sociais.

No caso do movimento de mulheres no Brasil vemos que existiu no período analisado (20032015) relação com a política interna, através da participação no Conselho Nacional dos Direitos da Mulher que foi se constituindo como um espaço de diálogo de construção de políticas públicas para as mulheres em âmbito nacional. Para a atuação cenário internacional os movimentos e organizações de mulheres preferiram se articular em redes internacionais, participar de fóruns internacionais, como o Fórum Social Mundial e influenciar na agenda internacional por meio de participação em organismos internacionais, ainda que de forma muito incipiente, por meio da ONU Mulheres, PNUD, CIFAL e UNITAR. A internacionalização do movimento de mulheres, ainda que tenha tido o apoio do Estado brasileiro no primeiro mandato do governo da então presidenta Dilma Rousseff, funcionou de forma autônoma com uma dinâmica própria na articulação com redes internacionais e fóruns de mulheres, deixando em segundo plano a relação institucional com o Ministério de Relações Exteriores do Brasil e com os organismos internacionais.

Com a mudança da conjuntura nacional a partir de 2016 os movimentos de mulheres no Brasil aderiram mais as atividades autônomas e participação nas redes internacionais fora dos 
espaços da institucionalidade e dos canais institucionais de participação. Com a tendência a uma ruptura democrática em alguns países da América Latina, entre eles o Brasil, vemos o aumento de mobilizações recentes articuladas internacionalmente contra a violência de gênero em várias cidades do mundo: como a campanha internacional "Nenhuma a Menos", de 2016 e a chamada Greve Internacional das Mulheres, convocada a partir do ano de 2017, no Dia Internacional da Mulher, dia o8 de março.

Ainda que o presente artigo trate de um momento histórico específico (2003-2015), vemos que a articulação do movimento de mulheres vem crescendo no mundo. A participação do movimento de mulheres no Brasil, através de suas lideranças entrevistadas, demonstra uma familiaridade com o tema da internacionalização tanto na articulação com o Estado, com o Ministério de Relações Exteriores e/ou com os organismos internacionais como na participação em redes e campanhas internacionais com outros movimentos sociais da América Latina e do mundo.

*Artigo recebido em 20 de abril de 2020, aprovado em 04 de julho de 2020.

\section{REFERÊNCIAS}

ABERS, Rebecca e VON BÜLOW, Marisa. Movimentos Sociais na teoria e na prática: como estudar o ativismo através da fronteira entre Estado e sociedade. Sociologias: Dinâmicas da Ação Coletiva, Porto Alegre, UFRGS, ano 13, $\mathrm{n}^{\mathrm{o}}$ 28, p. 52- 84, set/dez 2011. Disponível em: <www.seer.ufrgs.br/sociologias/article/download/24518/14154>. Acesso em 10/12/2020.

AVELAR, Lúcia. Movimentos, redes, feminismo de Estado: a representação extraparlamentar das mulheres brasileiras. Cadernos Adenauer, São Paulo, xiv nº 3. p. 71-87, 2013.

BRASIL. Presidência da República. Secretaria Especial de Políticas para as Mulheres. II Plano Nacional de Políticas para as Mulheres. 2a Reimpressão. Brasília: Secretaria Especial de Políticas para as Mulheres, 2008. 236 p.

BRASIL. Presidência da República. Secretaria Especial de Políticas para as Mulheres. Relatório Final de Implementação: I Plano Nacional de Políticas para as Mulheres - 2005 - 2007. Brasília: SPM, 2009.

Discurso da Presidenta Dilma Rousseff, por ocasião do Debate Geral da 66 ${ }^{\mathrm{a}}$ Assembleia Geral das Nações Unidas - Nova York, Estados Unidos, 21.09.2011.

FARIA, Carlos Aurélio Pimenta de. O Itamaraty e a Política Externa Brasileira: Do insulamento à Busca de Coordenação dos Atores. Contexto Internacional, Rio de Janeiro, vol. 34, no 1, p. 311355. janeiro/junho 2012.

LIMA, Maria Regina Soares de, MILANI, Carlos R.S. Reflexões sobre a política externa brasileira. CEBRI textos, Rio de Janeiro, p. 2-10, 2014. 
LINHARES, Leila. O Direito Internacional e o Movimento de Mulheres. Revista Estudos Feministas, Florianópolis, vol. 3, n.1, p. 191-197, 1995.

LOVENDUSKI, Joni. State feminism and political representation. 1 Ed. New York: Cambridge University Press, 2005.

MARX, Vanessa. A atuação e influência dos movimentos sociais no cenário internacional. In: Congresso Brasileiro de Sociologia 17 $\mathbf{1}^{\mathbf{0}}, 2015$ jul. Porto Alegre, Sociedade Brasileira de Sociologia, 2015a.

MARX, Vanessa. A relação dos movimentos sociais com a política externa brasileira. In: 39 Encontro Anual da ANPOCS GT14 - Entre as ruas e os gabinetes: institucionalização e contestação nos movimentos sociais latino-americanos, Caxambu, 2015b.

MELUCCI, Alberto. Um objetivo para os Movimentos Sociais? Revista Lua Nova, São Paulo, n.17, junho 1989. p.49-66.

MILANI, Carlos R. S; PINHEIRO, Letícia. Política Externa Brasileira: Os desafios de sua caracterização como Política Pública. Contexto Internacional (PUC), Rio de Janeiro, vol. 35, n. 1, p. 11-41 - jan/jun 2013.

MOHANTY, Satya, Literary theory and the claims of history: Postmodernism, objectivity, multicultural politics. New York: Cornell University Press, 1997.

PECEQUILO, Cristina Soreanu. Introdução às Relações Internacionais: temas, atores e visões. Rio de Janeiro: Editora Vozes, 2004.

RANGEL, Patrícia. Movimentos feministas e direitos políticos das mulheres. Brasília. Tese de Doutorado em Ciência Política. Instituto de Ciência Política, Universidade de Brasília, 2012.

RELATÓRIO NACIONAL BRASILEIRO. Relativo aos anos de 1985, 1989, 1993, 1997 e 2001, nos termos do artigo 18 da Convenção sobre a Eliminação de todas as formas de Discriminação contra a Mulher. Brasília, junho de 2002. Disponível em: <http://www.observatoriodegenero.gov.br/eixo/internacional/instancias-regionais/o-comitecedaw-2013-comite-para-a-eliminacao-de-todas-as-formas-de-discriminacao-contra-amulher/1relatorio-nacional-brasileiro-2002.pdf > . Acesso em 10/12/2020.

SCHERER-WARREN, Ilse. Movimentos sociais e pós-colonialismo na América Latina. Ciências Sociais Unisinos, São Leopoldo, vol. 46, n. 1, jan/abr, 2010. p.18-27.

SCHERER-WARREN, Ilse. Das Mobilizações às Redes De Movimentos Sociais. Sociedade e Estado, Brasília, vol. 21, n.1, p. 109-130, jan./abr, 2006.

SEGATO, Rita Laura. Gênero e colonialidade: em busca de chaves de leitura e de um vocabulário estratégico descolonial, E-cadernos, Porto. CES 18, p. 106 - 131, 2012.

SOUSA SANTOS, Boaventura. Produzir para viver: os caminhos da produção não capitalista. Rio de Janeiro: Civilização Brasileira, 2002.

MARCHA MUNDIAL DAS MULHERES. O que é a Marcha Mundial das Mulheres? Disponível em: < https://marchamulheres.wordpress.com/mmm/>. Acesso em 10/12/2020.

TARROW, Sidney. O Poder em Movimento: movimentos sociais e confronto político. Petrópolis: Vozes, 2009. 
TILLY, Charles. From mobilization to revolution. Ed. Reading, Mass, Boston: Addison-Wesley Publishing Co., 1978.

TOURRAINE, Alain. The study of social movements. Social Research, vol. 52, n.4, p. 749 - 787, 1985 . 